\title{
Marketing em questão: narrativas e impactos sobre a imagem pública e a gestão de museus
}

\author{
Marketing in question: \\ narratives and impacts on public image and museum \\ management
}

\author{
Rosane Maria Rocha de Carvalho' \\ DOI 10.26512/museologia.v9iEspecial. 31815
}

\section{Resumo}

As estratégias de Marketing em museus são instrumentos de gestão em instituições museológicas. Seu estudo e sua utilização ccontribuem para a Museologia Teórica e Aplicada, nas interfaces entre Museologia e Comunicação e a necessidade de implementar reflexões sobre os valores mais relevantes para os museus na atualidade: conexão, presença e experiência. As estratégias e técnicas de Marketing são apresentadas, tais como precificação, promoção e comunicação, distribuição externa de programas, construção de uma imagem de marca, pesquisa de audiência, Marketing de serviços, desenvolvimento de novos produtos, autoavaliação, utilizando desde planejamento estratégico, orçamento até publicidade, relações com a mídia e captação de recursos. Estas auxiliam os gestores de museus a atingir seus objetivos, a alcançar maior qualidade, a obter suporte mais amplo e a construir museus sustentáveis.

\section{Palavras-chave}

Museologia e Comunicação. Marketing em Museus. Desenvolvimento de Público. Mídias sociais. Museus sustentáveis.

\begin{abstract}
Museum Marketing strategies are management instruments in museum institutions. Their study and use contribute to theoretical and applied Museology on interfaces between Museology and Communication fields and contribute to the need to implement reflections on the most relevant values for museums today. Marketing technics and strategies are presented such as pricing, promotion and communication, external program distribution, a brand image, audience surveys, marketing services, development of new products, self-evaluation, using strategic planning budget and propaganda, including media relations and fundraising, which help museums managers to reach their objectives, obtain more quality, wider support and build sustainable museums.
\end{abstract}

\section{Keywords}

Museology and Communication. Museum Marketing. Audience Development. Social Media. Sustainable museums.

\section{Introdução}

As estratégias de Marketing em Museus são instrumentos de gestão amplamente utilizadas em museus pelo mundo. Seu estudo e utilização contribuem para a Museologia Teórica e Aplicada, nas interfaces entre Museologia e Comunicação. Atendem à necessidade de implementar valores relevantes para os museus na atualidade como a conexão com o público, a expressão de sua presença nas mídias, a sua função na vida dos indivíduos e de proporcionar uma

\footnotetext{
I Museóloga, MHN (1975) e Graduada em Comunicação Social, FACHA (1980). Especializada em Marketing e Relações Públicas em Museus - bolsa Fulbright (1995). Mestre (1998) e Doutora (2005) em Ciência da Informação pelo IBICT/ECO/UFRJ. Pós-doutorado, Programa de Pós-Graduação em Museologia e Patrimônio - PPG-PMUS, UNIRIO/MAST (2007). Coordenadora de Conteúdo, curso de Pós Graduação Lato Sensu (MBA) em Gestão de Museus, Universidade Candido Mendes - UCAM / ABGC-Associação Brasileira de Gestão Cultural. E-mail: carvalho.rosane2009@gmail.com
} 
experiência significativa e memorável para aqueles que se relacionam com suas exposições, propostas e atividades culturais.

O presente artigo parte da pesquisa "Marketing e Relações Públicas em museus norte-americanos", realizada em 1995 nos Estados Unidos como especialização em Museologia. Aquele estudo utilizou como instrumento a entrevista a especialistas naqueles museus e como métodos a pesquisa qualitativa e o benchmarking para obter as melhores práticas desenvolvidas naqueles museus, gerando um relatório. A referida pesquisa continuou a ser desenvolvida ao longo dos anos $(2006,2010,2017)$ com novas entrevistas nos museus estadunidenses.

\section{Objetivos}

Os objetivos deste artigo são descrever como se deu a introdução e desenvolvimento do uso das estratégias e técnicas de Marketing na administração de museus brasileiros, levando-se em conta os dados obtidos das entrevistas anteriores em museus norte-americanos, além de apresentar um quadro sobre as dificuldades de sua implementação.

Para cumprir com os objetivos propostos, foram relatadas experiências em instituições de patrimônio, como a Fundação Nacional proMemória e museus brasileiros além de levantada a bibliografia sobre Marketing em Museus brasileiros e estrangeiros. (KOTLER \& KOTLER, 1999; MCCARTHY, I960; IRWIN \& LAUTERBOR, I990; MCLEAN, I997;WEIL, 2004; MESSIAS, 20 I8;)

\section{Metodologia}

A metodologia utilizou a pesquisa descritiva, classificada quanto aos objetivos e a pesquisa bibliográfica para complementá-la.

A pesquisa descritiva, segundo Vergara (2000: 47) argumenta, expõe as características de determinada população ou fenômeno, estabelece correlações entre variáveis e define sua natureza. "Não têm o compromisso de explicar os fenômenos que descreve, embora sirva de base para tal explicação". Não se compromete com a relação de causa e efeito. Diferentemente, Castro (1976) considera que a pesquisa descritiva apenas "se limita a uma descrição pura e simples de cada uma das variáveis, isoladamente, sem que sua associação ou interação com as demais sejam examinadas" (CASTRO, I 976: 66).

A pesquisa bibliográfica, considerada uma fonte de coleta de dados secundária, pode ser definida como: contribuições culturais ou científicas realizadas no passado sobre um determinado assunto, tema ou problema que possa ser estudado (LAKATOS \& MARCONI, 200I; CERVO \& BERVIAN, 2002).

Para Lakatos e Marconi (200I:I83), a pesquisa bibliográfica,

[...] abrange toda bibliografia já tornada pública em relação ao tema estudado, desde publicações avulsas, boletins, jornais, revistas, livros, pesquisas, monografias, teses, materiais cartográficos, etc. [...] e sua finalidade é colocar o pesquisador em contato direto com tudo o que foi escrito, dito ou filmado sobre determinado assunto [...]. 


\section{Antecedentes}

Os antecedentes relacionados ao tema do Marketing aplicado aos museus são enriquecidos com os modelos teóricos de Neil Kotler e Philip Kotler (1999), segundo os quais o Marketing representa "um processo de troca entre quem procura um produto ou serviço e aqueles que podem fornecê-lo". $O$ conceito de Marketing neste contexto de museus é relativamente recente e muitos deles implementam novas técnicas sob pressão de diferentes partes interessadas (McLean, 1997: 37). Por outro lado, os visitantes de museus e os clientes são cada vez mais exigentes em termos de qualidade dos serviços que consomem, principalmente porque as ofertas alternativas de lazer utilizam o atendimento ao cliente como um instrumento competitivo. E para realizar atividades de Marketing é necessário criar um plano estratégico de Marketing, uma ferramenta essencial que permite à administração do museu concentrar seus esforços nos elementos e atividades que são vitais para atingir um público mais amplo e diversificado.

No século $X X$ os desafios enfrentados pelos museus, centros de história e ciência, zoológicos e jardins botânicos foram, até recentemente, a competição com outros museus e instituições culturais pelo público, pela implementação mais programas culturais e educativos, tendo recursos limitados e necessitando construir uma audiência mais ampla, gerar renda, renovar exposições e galerias, capturar o entusiasmo dos jovens e construir colaborações. As estratégias de Marketing em Museus fornecem uma estrutura para ações presentes e futuras no enfrentamento desses e de outros problemas. Um dos desafios mais prementes dos museus, segundo Neil Kotler e Philip Kotler (1999) revelam, é como os museus podem gerar receita, aumentar audiências e recursos, mantendo e avançando na sua missão. Em vez de ver o Marketing como incompatível com a missão, explicam a relação estratégica entre missão, público e financiamento - e como gerenciar essa relação é vital para um museu ser bem sucedido.

Segundo Messias (2018:278) em sua tese de doutorado na Universidade Lusófona de Lisboa, se considerarmos, como Weil (1990: 56), que a principal missão do museu é contribuir para o bem público, ou seja, ter um impacto positivo na vida das pessoas, os seus objetivos vão ser essencialmente de caráter social, o que implica entender o Marketing de uma perspectiva não comercial e inserido no contexto específico das organizações culturais e das suas particularidades. (MESSIAS, 20 I8). Neste sentido é esclarecedor o livro de Andreasen \& Kotler (2003), Strategic Marketing for Non-profit Organizations, (Marketing estratégico para instituições que não visam lucro).

\section{As estratégias e ferramentas de Marketing}

As ferramentas de Marketing são instrumentos que os profissionais de museus podem usar para moldar e atingir seus próprios objetivos, alcançar maior qualidade, suporte mais amplo e construir museus sustentáveis e vibrantes. Hoje os gestores contam com uma variedade de métodos e ferramentas para lidar com condições de mudanças rápidas: precificação, promoção e comunicação, distribuição externa de programas, construção de uma imagem de marca, pesquisa de audiência, Marketing de serviços, desenvolvimento de novos produtos, autoavaliação e atualização do planejamento de Marketing, usando desde planejamento estratégico e orçamento até publicidade, relações com a 
mídia e captação de recursos.

Para Messias (2018) atualmente tanto no Marketing como na comunicação cultural assiste-se a um maior enfoque no consumidor ou audiência (e não no produto ou colecção) que deixam de ser encarados como sujeitos passivos destinatários de informação.

Esse fato levou à substituição das tradicionais variáveis básicas do Marketing, os denominados 4Ps (preço, local, produto/serviço e promoção) pelos 4Cs (custo para o consumidor, conveniência, necessidades e desejos do consumidor e comunicação) que vão colocar o consumidor no centro da estratégia (MCCARTHY, I960; IRWIN e LAUTERBOR, 1990) e permitem ajudar os profissionais de Marketing a atingir níveis de personalização muito avançados, ou seja, quanto mais adaptada a cada perfil estiver uma mensagem, maior relevância ela vai ter para o seu público-alvo.

Estas estratégias são aplicadas e desenvolvidas em museus por todo mundo e contam com seminários e congressos específicos: Museum Next, Communicating the Museum e constituem um comitê especifico no Conselho Internacional de Museus-ICOM na sigla em inglês, chamado Marketing and Public Relations in Museums-MPR. Nos museus norte-americanos recebem o nome de Desenvolvimento (Development), conceito de Marketing expandido.

\title{
O Desenvolvimento de público
}

Dentre as técnicas de Marketing está o desenvolvimento de público. A pesquisa Marketing e Relações Públicas em Museus apresentada no Encontro Nacional de Pesquisadores em Ciência da Informação no Brasil-ENANCIB, relata que o Desenvolvimento de Público desde os anos 1980 tornou-se a meta principal dos museus norte-americanos. Esta técnica é uma diretriz que perpassa todos os setores de um museu visando atrair um novo visitante, manter o visitante habitual e atingir novos segmentos de público. Trata-se de uma meta estratégica e é coordenada pela alta direção do museu e vista como essencial para assegurar o crescimento e a sobrevivência do museu no século $X X I$.

Pamela McDonald (1999:17), mestre em Marketing e Diretora de Desenvolvimento de Público dos Museus de Belas Artes de São Francisco, Estados Unidos, afirma:

\begin{abstract}
Visitar museus é uma atividade de lazer, e o tempo de lazer está se tornando escasso para muitas pessoas, moradores locais e turistas. Devido às muitas opções que competem por esse tempo de lazer limitado, o cliente em potencial faz, consciente ou inconscientemente, uma análise de custo-benefício. $O$ modelo de tomada de decisão mental funciona mais ou menos assim: Será que os benefícios de entretenimento antecipados nessa ou naquela atividade específica superam significativamente os custos, riscos e possíveis desapontamentos antecipados associados àquela atividade? Será que uma visita ao museu vale a pena? (MCDONALD, 1999:I8)
\end{abstract}

Nas grandes cidades os museus e outras instituições culturais precisam competir por um público diversificado e com interesses variados. Qual seria a vantagem de uma visita a um museu em relação a outras atividades, uma pessoa deve se perguntar. 
Baseado no que aprendemos com as pesquisas de público, um museu que procura enfocar as pessoas, e não os objetos, fará sucesso nesse mercado. Com "enfocar as pessoas" quero dizer que o museu procuraria chamar a atenção para a diversidade populacional de sua cidade e faria uma programação de exposições que refletisse a excelência de várias culturas. (MCDONALD, 1999:18)

Confirmando esta perspectiva, Messias (2018: 280) afirma ser importante identificar as características que o museu possui que possam diferenciá-lo e ajudar a posicionar-se de um modo chamativo evidente no seu entorno (mercado) cultural. Para tal tem sido crescente a importância do branding (gestão da marca) das instituições, de modo a definir a sua marca, em referência aos valores que pretende transmitir e aos atributos que lhe são associados, assim como a sua estratégia de comunicação e de relacionamento com a audiência.

Um outro exemplo do priorizar as pessoas leva em conta, integralmente, tanto as questões humanas que envolvem a interpretação do acervo quanto as suas necessidades que implicam em serviços eficientes ao consumidor visando a maximização da experiência do visitante. Acesso a transporte, facilidade de estacionamento, banheiros, acesso a deficientes físicos, etiquetas dos itens do acervo em vários idiomas, folhetos e visitas guiadas, conforto para refeições, lojas de lembranças bem equipadas, facilidades, programas especiais para famílias com crianças e locais para encontros são alguns tipos de modificações de escala humana que podem tornar os museus competitivos na mente do consumidor em relação a outras opções de lazer. (MCDONALD, 1999:19)

A área de Desenvolvimento de Público daquele Museu de Belas Arte de São Francisco foi criada em 1990, devido à mudança nas fontes de recursos, e, consequentemente, os museus terem a necessidade de expandir a função de Marketing na sua organização. Seu conselho curador desenvolveu um Plano de Desenvolvimento de Público com 9 metas e com 46 objetivos específicos a serem atingidos em 5 anos. Para tanto a especialista em Marketing Pamela McDonald foi contratada. Um componente decisivo do plano foi a institucionalização de um processo contínuo de autoexame na forma de constantes pesquisas de opinião, quantitativas e de avaliação das exposições, qualitativa, junto aos visitantes. "Essa pesquisa quantitativa permitiu avaliar o progresso em relação à implementação das metas e objetivos do Plano.

As principais metas deste plano consistiam em: aumentar a frequência de visitantes; assegurar o acesso do público; atrair um público mais diversificado para que se torne associado ao museu; informar aos associados, à comunidade e ao público sobre o museu e suas atividades; prestar atenção na reação do visitante; envolver a comunidade no planejamento futuro do museu; educar o público e promover a imagem local, regional, nacional e internacional do museu. Estas são ainda as metas atuais para os museus em geral.

Tendo em vista que as verbas públicas cada vez são mais escassas, que as privadas são difíceis de conseguir e, que, a arrecadação obtida com a venda de ingressos e produtos nas lojas, pelo menos nos Estados Unidos e na Europa, tornam-se cada vez mais importantes no incremento do orçamento dos museus, ampliar o público visitante é fundamental. Então para atrair novos públicos, uma instituição precisa fazer uma introspecção e estar disposta a conduzir as mudanças necessárias, tanto quanto qualquer outro empreendimento o faria. 


\section{O impacto das TICs e o Marketing Digital}

Nas primeiras décadas deste século $X X I$, as instituições que sobreviveram ao anterior enfrentam novos desafios, alguns muito grandes. Mudanças tecnológicas, como o uso intensivo de smartphones, robótica, big data e tudo mais, combinadas com as sociais que as acompanham - incluindo a tremenda pandemia que estamos enfrentando - como a mudança de necessidades educacionais, novas formas de trabalho ou novas estruturas ameaçam a existência de instituições que resistem à evolução - sem terminar de se adaptar - e que pensam que este século será como o século anterior. Os museus, como outras instituições que representam nossa cultura, patrimônio e arte, não são excluídos dessa tendência de medo da mudança. $\bigcirc$ que está mudando?

O impacto das TICs (Tecnologias da Informação e Comunicação) na sociedade e a sua adoção pelos museus (websites, comunidades online, mídias sociais, aplicativos para celulares etc.) afetou tanto o perfil da audiência, os seus hábitos, competências e necessidades, como as técnicas e estratégias de Marketing (RICHANI, PAPAIOANNOU \& BANON, 2016) das instituições que cada vez mais apostam nos ambientes online e no envolvimento digital, assumindo-se na década anterior os websites e a redes sociais como as principais ferramentas de Marketing para os museus (DEVINE, 2008: I4).

O Marketing digital tornou-se um dos principais aliados das instituições culturais, graças à sua capacidade de comunicar com a audiência no momento certo, de uma forma direta e personalizada, sem necessitar de um grande investimento financeiro. $O$ Marketing online vai permitir adicionar uma identidade digital à realidade física da instituição, distribuir mensagens através de múltiplos canais e ampliar as audiências. Permite também manter uma interação contínua com a audiência estabelecendo uma relação de maior proximidade. Possibilita também às pessoas interagir com os conteúdos disponibilizados de forma fácil e geralmente em tempo real, indo cada vez mais no sentido da personalização, ou seja, entregar a mensagem certa às pessoas certas na hora certa.

O Marketing digital (da Web 2.0) permite uma comunicação mais democrática de vias múltiplas, aberta e centrada nas comunidades de interesses e com alcance global (sem restrições quanto a limites geográficos) fomentando a interação das pessoas com os conteúdos disponibilizados na rede. Entre os vários canais de distribuição e ferramentas do Marketing digital estão os blogs, o e-mail, as redes sociais, o Marketing em vídeos, destacando-se o Facebook um fenômeno pelo eu prolongado uso e número de acessos.

\section{O Marketing relacional e a cocriação}

O Marketing relacional, parte integrante do desenvolvimento de públicos, é uma estratégia para atrair, manter e melhorar a relação com o cliente, a sua lealdade e fidelização, tendo como base uma relação de credibilidade, segurança e confiança (RAVALD \& GRÖROOS, I 996; EGAN, 20I I). Kotler \& Kotler (2008: p.26) integram o Marketing relacional dentro do conceito mais holístico de Marketing de museus como o processo que procura estabilizar e manter as interações com os consumidores. $O$ autor enfatiza que o Marketing relacional pretende criar um suporte para uma relação a longo termo através da criação de relações contínuas e duradouras entre todos os interessados, desde o staff à direção, membros, doadores, visitantes, a comunidade circundante e restante 
audiência potencial. Para tal é desenvolvida uma comunicação constante e persistente através de diversos media e canais, que vai favorecer o envolvimento e a participação, a conversação, a colaboração e a criação de comunidades em torno da instituição. (MESSIAS, 20|8: 283)

Os museus podem nos trazer de volta à uma realidade mais humana, se conectando aos seus diversos públicos utilizando mais a tecnologia, se comunicando através das mídias sociais e se engajando em causas que beneficiem as comunidades no seu entorno, em círculos que se alargam, fazendo-as participar, acolhendo suas contribuições e tratando das questões humanas solidariamente. Abordar estas questões numa curadoria cuidadosa observando a sua missão deverá aumentar a sua relevância junto à sociedade. (VISSER, 20I2)

Para isso, necessitam trabalhar seu valor, atuar com comunidades ativas e participativas, mostrar seu comprometimento e estarem abertos à cocriação. Ao abordar "valor" devemos entender num sentido mais amplo. $O$ atendimento rápido e amigável ao cliente, por exemplo, pode ter custos financeiros significativos, mas, se feito corretamente, aumenta muito o valor da marca e a lealdade do consumidor. Por outro lado, o conceito de "valor" tem muitas nuances: financeira, social, política, emocional, educacional, criativa... Estar ciente de que todas estas formam um sistema que, com pouco de criatividade, ajuda os museus a se tornarem relevantes, cumprir seus orçamentos e agregar valor à sociedade.

Comunidades ativas e participantes são grupos de pessoas que se reúnem regularmente e criam juntos (online ou em outros lugares) em torno de seus interesses, metas ou valores compartilhados. Às vezes, é mais fácil tirar proveito das comunidades existentes do que tentar construir novas do zero. $\mathrm{Na}$ Internet existem muitas e os museus devem identificar as que se correspondem aos seus propósitos. Jasper Visser (20I2) elabora também uma extensa lista de ações fáceis de realizar para ajudar as instituições culturais a beneficiarem da utilização das novos mídias, tais como partilhar fotos dos eventos ou divulgar vídeos de debates e palestras realizados na instituição em plataformas populares, entrevistar os visitantes e publicar as entrevistas online, entre outras. A maioria destas comunidades não é grande, mas sua energia é potencial. A tecnologia não é um ingrediente obrigatório para uma comunidade, mas quando usada com sabedoria, pode aumentar seus esforços. (VISSER, 20I2)

Por outro lado, Bautista (20I3) vai também desenvolver a noção de "comunidades interpretativas" mais focada no ambiente online, onde identifica: "comunidades de interesse" (constituídas por pessoas de diversas origens que partilham os mesmos interesses); "comunidades de questionamento" (buscam responder às mesmas questões, com as mesmas dúvidas e necessidades de aprendizagem, por exemplo as que procuram cursos online); e "comunidades de práticas/conhecimento" (com interesses, objetivos e práticas comuns tais como o discurso e a transferência de conhecimento priorizando as relações sociais entre os membros, como fóruns e wikis de natureza colaborativa e social), que necessitam ser reconhecidas e contempladas nas estratégias de envolvimento digital.

O comprometimento, digital ou não, é o elemento mais importante para o desenvolvimento de um relacionamento entre pessoas e instituições que contam com acervos. Se os museus não ativarem seu público de tempos em tempos, eles o perderão para os concorrentes que oferecem uma oportunidade de participar (uma conversa na galeria de exposições transmitida pelo Facebook, interação nas reuniões no Zoom com temáticas de interesse ou acolher as su- 
gestões de seus vizinhos).

Cocriação é uma forma de inovação que acontece quando colaboradores, fornecedores, e clientes associam-se com o negócio agregando valor, conteúdo, conhecimento e experiências. Em troca recebem os benefícios de sua contribuição, seja através do acesso a produtos customizados ou da promoção de suas ideias. (MAEDA: 2020)

A cocriação é um processo através do qual uma instituição e seu público-alvo trabalham juntos para gerar valor. Ambos fazem o que sabem melhor e juntos alcançam algo de bom para os dois. A cocriação é a base de qualquer modelo de parceria. $O$ que a torna especial é a compreensão mais ampla do valor que os museus podem ter e das comunidades ativas e participantes que são a base do século XXI.

Uma instituição social é uma entidade que envolve estruturalmente seus stakeholders para cocriar valor. Acreditamos que os museus (e outras instituições), com o passar do tempo, se tornarão cada vez mais instituições sociais, voltadas para engajar todos estes grupos em atividades mais personalizadas e criativas ${ }^{2}$.

Os museus criam valor quando tratam tanto do que pode ser agregado (imagem positiva e reconhecimento de sua marca, novos públicos, stakeholders) quanto do que podem contribuir, isto é, suas capacidades e características únicas (coleção, curadores, pessoal especializado, edifícios etc.) que são a base de sua contribuição e, portanto, são valiosas e valorizadas pelos interessados.

As redes sociais são veículos eficazes e uma boa maneira de comunicar sobre a transição das instituições tradicionais para as sociais. Possivelmente a chave para os museus enfrentarem esses tempos de mudança social e tecnológica (e saúde) será tornarem-se instituições mais sociais, cocriando valor com nossas comunidades.

\section{O Marketing e os Museus brasileiros}

Nos museus brasileiros as instituições museológicas públicas têm usado pouco as estratégias de Marketing. As políticas públicas culturais contemplaram até agora os instrumentos de fomento e financiamento de atividades culturais.

\section{Foi nesse sentido que o [Ministério da Cultura] MinC e demais ór- gãos federais estabeleceram políticas de financiamento e fomento a museus, via Fundo Nacional de Cultura, Mecenato e Editais como os de Modernização de Museus (IPHAN/MinC), Adoção de Entida- des Culturais (CEF), Preservação de Acervos (BNDES) e Apoio à Cultura-Patrimônio (Petrobras). (IBRAM, 20I0).}

Porém falta uma política cultural que estimule e preconize este conjunto de estratégias de Marketing para disseminar a um público mais amplo os seus acervos, exposições, programação cultural e os serviços que prestam. E dessa forma acabar com o preconceito contra esta disciplina, associada apenas a questões comerciais e que retiraria o valor intrínseco do patrimônio conservado e transformaria os museus em comércio.

A visitação dos museus públicos no Rio de Janeiro ainda é pequena ante

2 Stakeholder é um termo da língua inglesa que tem como significado "grupo de interesse". Fazem parte deste grupo pessoas que possuem algum tipo de interesse nos processos e resultados da empresa como o conselho de administração, o de gestão de empresas, funcionários, acionistas, fornecedores, clientes e os municípios em que a empresa atua, onde estão ativamente envolvidas no projeto ou há algum interesse afetando positivamente ou negativamente a execução do projeto. 
o seu potencial e a excelência de seus acervos. A exceção são os museus situados em destinos turísticos, como o Museu Imperial em Petrópolis e aqueles geridos por organização social de cultura, pois desenvolvem modelo de gestão semelhante ao das empresas privadas, focado nos resultados de manutenção do acervo, incremento da coleção, atendimento a escolares, aumento da visitação e fidelização do público. Necessitam de Marketing para desenvolver públicos, angariar notoriedade, consagrar sua marca e obter patrocínios e parcerias que viabilizem a sua sustentabilidade financeira.

Por outro lado, museus e instituições culturais no país tem desenvolvido pesquisas de público desde os anos 1990, procurando identificar o seu público visitante e o não-visitante, prática que vem se realizado até hoje, dada a sua importância como identificação dos segmentos de público que visitam as instituições museológicas.

Porém os museus e a área de patrimônio cultural são muito resistentes às mudanças e às contribuições das estratégias de Marketing.

$A$ resistência às atividades de Marketing nos museus e na área de patrimônio histórico nos fazem retroceder a 1987 quando a Fundação Nacional proMemória, órgão executivo da Secretaria do Patrimônio Histórico e Artístico Nacional-Sphan, criou a Assessoria de Marketing, coordenada por um especialista em Marketing que havia atuado em diversos setores do Jornal do Brasil (JB), dentre eles na comunicação interna, na editora JB e na agência JB, onde desenvolveu ações de Marketing direto.

Este novo assessor fez viagens pelo país conhecendo coordenadorias regionais da Sphan/ProMemória e museus. Após este mapeamento e diagnóstico das necessidades da instituição realizou um seminário interno para apresentar a Assessoria de Marketing e seus projetos de fortalecimento da marca a diretores de museus, das regionais e chefias. Alguns destes líderes e muitos funcionários reagiram fortemente à esta mudança de visão que colocaria as instituições na mente de um público mais amplo. Foram apresentados projetos para desenvolver ações utilizando as ferramentas de Marketing direto, segmentação de público, Marketing institucional, pesquisa de potenciais patrocinadores, criação de produtos - como as toalhas das bandejas da Varig, utilizadas nas refeições em seus voos pelo país, com desenhos elaborados de bens tombados como arquitetura colonial, igrejas, casario e outros bens com a marca Sphan/ProMemória - e de jogos e brinquedos para venda nas lojas de museus, iniciando com 4 jogos de quebra-cabeças com a imagem de 4 importantes pinturas do Museu Nacional de Belas Artes, em parceria com a empresa Coluna Brinquedos de São Paulo. Os produtos e jogos foram bem aceitos pelo público.

O pensamento conservador destas lideranças habituadas a disporem de poucos recursos para executarem seu desafiador trabalho de preservação de bens culturais em suas instituições, sem o conhecimento da necessidade de ampliar a consciência pública a respeito de seu valioso trabalho e a atualização sobre os benefícios destas novas estratégias, provocaram resistência. Apesar disso a assessoria de Marketing conseguiu I 4 patrocinadores privados, 4 instituições culturais estrangeiras e apoio de mídia de 3 veículos de comunicação para a realização de 2 eventos de primeira grandeza.

O primeiro, "Seminário Museus Nacionais; perfil e perspectivas" no Rio de Janeiro em julho de 1988, reuniu palestrante nacionais e estrangeiros que falaram a uma plateia qualificada do setor cultural de 600 pessoas a cada um de seus 3 dias sobre a necessidade da ampliação dos quadros de pessoal das insti- 
tuições museológicas públicas para equipes multidisciplinares contemplando a contribuição de profissionais que não apenas museólogos, arquitetos e restauradores, mas também os das áreas de comunicação, Marketing, semiótica, história, gestão financeira e outros, além da formação de associações de amigos, afim de atrair mais visitantes, criar maior conexão com suas audiências e obter apoio financeiro da iniciativa privada para seus projetos e realizações. A Assessoria citada conseguiu apoio de empresas para trazer palestrantes do exterior (Estados Unidos e Portugal) e de outros estados brasileiros, que financiaram passagens aéreas e hospedagem para este grupo de convidados. O seminário impactou os museus nacionais com novas abordagens e sugestões para sua gestão. Também gerou uma edição especial do Boletim Sphan/ProMemória (1988), que, além das palestras, descreveu as novas iniciativas da Assessoria de Marketing, objetivando maior consciência do público interno e colaboradores das instituições Sphan e ProMemória que foram reunidas a partir de 1979.

O segundo evento, que também gerou boa repercussão no campo e na imprensa, foi o $2^{\circ}$ Congresso Internacional do Barroco no Brasil em Ouro Preto em setembro de 1989, que reuniu especialistas brasileiros e estrangeiros, dentre eles o historiador da arte francês, Germain Bazin, na época o maior autor sobre a arte barroca e as obras de Aleijadinho.Várias empresas privadas participaram destes 2 eventos com seu patrocínio, trazidas pela Assessoria de Marketing.

Quanto às atividades de Marketing no país, as de desenvolvimento de público que, por serem estratégicas, contavam com uma diretoria no museu de São Francisco, no Brasil hoje existe apenas um departamento com o mesmo título e dedicado aos mesmos objetivos no Museu do Amanhã no Rio de Janeiro, criado em 2015. Nos demais museus a função de Marketing não é explicitamente nomeada e é exercida pela área de comunicação. Aqueles geridos por uma Organização Social - OS no Rio de Janeiro, como o Museu de Arte do Rio e o Museu do Amanhã, desde o seu planejamento contaram na sua estrutura com equipe e orçamento para comunicação, Marketing e gestão de mídias sociais. Nos museus de São Paulo, grande parte geridos por OSs há uma consciência maior e se estruturam da mesma forma na prática.A Pinacoteca do Estado realizou campanhas de propaganda produzidas em parceria com agências de publicidade apresentando vídeos e anúncios veiculados nas mídias sociais, assim como banners para a fachada do prédio contemplando temas da campanha. Este museu também criou um aplicativo para celulares com a finalidade de apresentar suas obras do acervo, exposições e programação visual além de informar os horários de visita, permitindo ao visitante acesso e rapidez na obtenção de informações.

Muitos museus da atualidade dispõem de equipes e recursos para gerir as mídias sociais. Porém outras instituições museológicas, apesar da escassez de recursos financeiros e contarem com equipes mínimas, fazem um grande esforço para estarem presentes nestas mídias e terem alguma presença online.

\section{Capacitação em Marketing para museus}

Por todos estes motivos relatados, causados pelo pouco conhecimento sobre as possibilidades e benefícios do Marketing, gerou-se uma resistência à sua utilização por parte de instituições culturais nos anos 1980 e 1990 do século passado. Tornou-se necessária a contribuição das disciplinas Comunicação e Marketing na capacitação de gestores de museus, atuais e futuros. Para atender a esta carência de informações e conhecimento foi criado o curso de 
pós graduação MBA (Master of Business Administration) em Gestão de Museus na Universidade Candido Mendes em convênio com a Associação Brasileira de Gestão Cultural-ABGC no Rio de Janeiro, o primeiro no país. No momento de elaborar o conteúdo - disponibilizou-se um módulo exclusivo com 5 disciplinas a respeito de Comunicação e Marketing em Museus, temática não contemplada em cursos de graduação e pós graduação em Museologia ou em Marketing até os dias atuais no Brasil.

Este curso, criado em 2014 e tendo formado 3 turmas a cada 2 anos, tem como objetivos formar e reciclar profissionais atuantes no campo de museus; proporcionar uma visão integrada das áreas que suportam a gestão em museus como financiamento e sustentabilidade, modelagem de projetos, captação de recursos, posicionamento e branding, legislação, gestão de acervos, desenvolvimento de público pesquisas de público, pesquisa e produção de conhecimento, documentação e conservação, comunicação, Marketing e tecnologias da informação; profissionalizar novas gerações de museólogos, gestores, empreendedores e produtores culturais para atuarem nos museus.

As disciplinas do referido módulo versam sobre as "Estratégias de Comunicação e Marketing", abrangendo conceitos destas áreas, o planejamento de Marketing, as características do Marketing mix (produto, preço, praça, promoção e pessoas, chamados os 5Ps) e do composto de Comunicação (relações públicas, publicidade, assessoria de imprensa e divulgação) especificamente voltados para museus. Tratam também do funcionamento integrado destes setores na estrutura interna de museus brasileiros e estrangeiros e dos modelos de gestão de museus apoiados nas ferramentas de Marketing e Comunicação. Estas ferramentas reunidas deflagram a estratégia promocional voltada para o desenvolvimento de público e o financiamento de suas atividades principais. Incluem a contribuição das associações de amigos voltadas tanto para indivíduos como para empresas e as receitas financeiras geradas pelos eventos especiais, publicações, livrarias, lojas, design de produtos e restaurantes. Além de captar recursos estes setores intensificam a comunicação do museu com os diferentes segmentos de público, engajando-os, atraindo novos públicos. A geração de receita proporciona inclusão social através de programas com as comunidades de seu entorno.

A disciplina "Branding e Posicionamento institucional", além da construção da marca e da identidade do museu trata o posicionamento institucional como norteador da sua oferta de produtos e serviços voltados para a longevidade e a sustentabilidade financeira do museu. Os valores da marca diferenciam o museu dos demais, enfatizando a atração e fidelização de públicos, geração de receita própria e impactando os programas de assinaturas e sócios.

A "Formação e Desenvolvimento de Públicos" aborda as pesquisas de público, as de avaliação de exposições e as de hábitos culturais como ferramentas para novas estratégias que apontam para a programação de atividades culturais direcionadas para segmentos de público específicos, como crianças, adolescentes, famílias, terceira idade e pessoas com deficiência. Estimula as manifestações dos visitantes na saída das exposições, nas mídias sociais, acolhendo suas sugestões e opiniões.

A disciplina "Comunicação Digital” é voltada para o uso das tecnologias da informação no relacionamento com os públicos, o potencial dos museus na internet, os museus virtuais, a criação de redes colaborativas possibilitando o desenvolvimento de um plano de Estratégia Digital para cada museu, com ênfase nas mídias sociais. 
E, finalmente, a disciplina "Inovação em Museus" que versa sobre estudos de vocação institucional, programas de requalificação de museus, exemplos de melhores práticas, posturas inovadoras nacionais e internacionais, além do acolhimento qualificado do visitante no museu voltado à sua individualização, fruição, escuta e relação de afeto.

Todos estes conteúdos são importantes para o conhecimento e capacitação de um gestor, seja ele o diretor geral de um museu, seja o chefe de um departamento ou de setores técnicos. A compreensão da dimensão agregadora do Marketing, faz com que estes profissionais possam usar as técnicas já mencionadas para desenvolver e revitalizar os museus nos quais atuarem, propondo estratégias que reforçarão sua marca e imagem. Estas atividades devem valorizar a função social dos museus, tornando-os mais inclusivos e acessíveis, sem prejuízo da preservação de seus acervos e da pesquisa museológica.

\section{Considerações finais}

Além do desconhecimento geral sobre as contribuições do Marketing para os museus, a explosão planetária da doença do corona vírus COVID-19 no ano de 2020 deixará mudanças profundas na realidade econômica e social dos países. Os museus como todas as outras atividades, no momento pós pandemia, para adaptação à nova realidade, deverão assumir na sua gestão novos valores voltados às comunidades do seu entorno e ações dentre as quais distanciamento social, uso da tecnologia, austeridade nas finanças e nos hábitos, principalmente. O planejamento de Marketing deverá considerar estas necessidades e comunicar estas mudanças ao público. Deve prever protocolos de distanciamento e assepsia, além do aumento do uso da tecnologia e conectividade: no cenário de imobilidade global, a internet e outras inovações tecnológicas são importantes para manter atividades econômicas e sociais. Devido às restrições de visitação presencial, em função da segurança de seus funcionários e do público, os museus devem trabalhar com o aumento do trabalho à distância (home office) e a necessidade de comunicação remota, capacitando suas equipes e preparando as pessoas para essa nova realidade.

Reconhece-se também que à semelhança do que se têm verificado ao longo da sua história, os museus como instituições que refletem continuamente a sociedade a que pertencem, têm procurado dar resposta aos novos desafios que lhes têm sido colocados em consequência da intensificação de processos de globalização, das migrações, mudanças sociais e tecnológicas, procurando ser relevantes, focados no desenvolvimento sustentável, no progresso e bem-estar social dos públicos aos quais serve.

\section{Referências}

ANDREASEN, A. R., \& KOTLER, P. Strategic Marketing for Non-profit Organizations (6th. ed.). Upper Saddle River, NJ: Prentice Hall, 2003.

ASSOCIAÇÃO BRASILEIRA EM GESTÃO CULTURAL e UNIVERSIDADE CANDIDO MENDES. MBA em Gestão de Museus. Rio de Janeiro:ABGC, 2014. Disponível em: https://www.abgc.org.br/mba-em-gestao-de-museus/\#tab-id-2. Acesso em: 2 abr. 2020. 
BAUTISTA, C. Social media users say Pinterest is as popular as Twitter. 20I 3. Disponível em: Http://mashable.com/2013/02/I5/socil-media-pew-study/. Acesso em: 3 maio 2020.

SPHAN/PROMEMÓRIA. Boletim Museus Nacionais: perfil e perspectivas. Edição especial.V.42. Rio de Janeiro: Fundação Nacional pró-Memória, ago. 1988.

CARDOSO, Luisa Duarte. Gestão e Inovação nas Políticas Culturais para Museus: o sistema francês de museus nacionais. Escola de Comunicação/UFRJ. Rio de Janeiro: 2008. (Monografia) Disponível em: https://pantheon.ufrj.br/bitstream/I I 422/ 1742/I/ LCardoso.pdf .Acesso em: 20 maio 2020.

CARVALHO, Rosane M. R. Museus: novos aspectos informacionais e comunicacionais. XI ENANCIB GT 9: Museu, Patrimônio e Informação. Rio de Janeiro, ANCIB, 2010. 17 p. Disponível em: http://enancib.ibict.br/index.php/enanci/xienancib/ paper/viewFile /3599/2723 .Acesso em: 20 set.20I8.

CARVALHO, Rosane M. R. Museu: novos aspectos informacionais, comunicacionais e gerenciais. XII ENANCIB. Brasília, 20I I. Disponível em: http://200.20.0.78 /repositorios/bitstream/ handle//23456789/2070/Museu\%20-\%20Carvalho.pdf? sequence $=1$. Acesso em: 9 ago 2019 .

CASTRO, C. M. Estrutura e apresentação de publicações científicas. São Paulo: McGraw-Hill, 1976.

CERVO,A. L. \& BERVIAN, P.A. Metodologia científica. 5.ed. São Paulo: Prentice Hall, 2002.

DIMAGGIO, P.When the profit is quality. Museum News. Washington, DC.:American Association of Museums, Jun 1985, 63(5), 28-35.

DIMAGGIO, P., USEEM, M. \& BROWN, P. Audience Studies of the Performing Arts and Museums:A Critical Review. Washington, DC.: National Endowment for the Arts, 1978.

DEVINE, J. Partnerships for Progress. In: MARTY, P. F., \& JONES, K. B. Museum informatics: People, information, and technology in museums (Vol. 2), New York and London:Taylor \& Francis Group, 2008.

EGAN, J. Relationship Marketing. United Kingdom: Pearson Education, 20 I I.

INSTITUTO BRASILEIRO DE MUSEUS-IBRAM. Política Nacional de Museus. Brasília: Ibram, 20I0. Disponível em: https://www.museus.gov.br/wpcontent/uploads/2010/0I/ politica_nacional_museus.pdf.Acesso em 19 out. 2018.

IRWIN, R. \& LAUTERBORN, B. New Marketing Litany: Four Ps Passé: C-Words Take Over. In: Advertising Age. 1990. 6 I (4I), 26. Disponível em: http://rlauterborn. com/pubs/pdfs /4_Cs.pdf.Acesso em: 28 maio 2020.

KOTLER, N. G., KOTLER, P, \& KOTLER,W. I. Museum Marketing and strategy: De- 
signing missions, building audiences, generating revenue and resources ( 2 nd ed.). San Francisco, CA: Jossey-Bass, 2008.

LAKATOS, E. M. \& MARCONI, M. A. Fundamentos da metodologia científica. 4.ed. São Paulo:Atlas, 200I.

MAEDA, Tati. Entenda como funciona a cocriação. 2004. Disponível em: http://superstorm.com.br/inovacao/entenda-como-funciona-a-cocriacao. Acesso em: I5 abr. 2020.

MCCARTHY, E. J. Basic Marketing: A managerial approach. Homewood, Illinois: Richard D. Irwin, Inc., I 960.783 p.

MCDONALD, Pamela Mays. Desenvolvimento de público, turismo cultural e artes em São Francisco, Califórnia. CARVALHO, Rosane M. R. et al (org.). Cadernos de Memória Cultural 4-Museu em Transformação: as novas identidades dos museus. Rio de Janeiro: Museu da República, 1999. I68 p. p.I3-2I.

MCLEAN, F.A Marketing Revolution in Museums? Journal of Marketing Management, II, I995. p. 60I-6I6.

MCLEAN, F. Marketing the Museum. London and New York: Routledge, 1997.

MESSIAS, Maria José Miguel. As Tecnologias de Informação e Comunicação na Democratização do Museu: Estratégias Digitais Participativas e Inclusivas! Universidade Lusófona de Humanidades e Tecnologias, FCSEA - Instituto de Educação. Lisboa, 2018 (tese de doutorado). Disponível em: http://recil.grupolusofona.pt/ bitstream/handle/I 0437/9550/tese\%20doutoramento\%20maria\%20messias\%20 com\%20j\%C3\%BAri.pdf?sequence=I.Acesso em: 10 jan. 2019.

O GLOBO. 0 mundo não será o mesmo após o coronavírus. Conheça 6 forças que moldarão o futuro. Rio de Janeiro: 2020. Disponível em: https://oglobo. globo.com/economia/o-mundo-nao-sera-mesmo-apos-coronavirus-conheca-6-forcas-que-moldarao-futuro-2443 |458?utm_source=aplicativoOGlobo\&utm medium=aplicativo\&utm_campaign=compartilhar.Acesso em: 20 maio 2020.

RAVALD, A., \& GRÖNROOS, C. The value concept and relationship Marketing. European Journal of Marketing, 30(2), 1996. P. 19-30. Disponível em: http://www. emeraldinsight.com/doi/pdfplus/10.1 108/030905696/0106626. Acesso em: I8 out. 2008.

REMELGADO, Ana Patrícia S. L. Estratégias de Comunicação em Museus Instrumentos de Gestão em Instituições Museológicas. Porto: Faculdade de Letras da Universidade do Porto, 2014 (Tese de doutorado) 439 p. Disponível em: https:// repositorio-aberto.up.pt/bitstream/I02 I6/I093 I5/2/234I 22.pdf. Acesso em: I4 maio 2020.

RICHANI, E., PAPAIONAMOU, G., \& BANOU, C. Emerging opportunities: the Internet, Marketing and museums. In: MATEC. Web of Conferences (Vol. 76). EDP Sciences, 2016. Disponível em: https://www.matecconferencesorg/articles/ ma- 
RICHARDSON, Jim (2019): Quirky Marketing Ideas That Helped Museums Stand Out. Museum Next.Washington DC.:American Alliance of Museums, 2019. Disponível em: https://www.museumnext.com/article/quirky-Marketing-ideas-that-helped-museums-stand-out/ Acesso em: 20 mar 2019.

VERGARA, Sylvia C. Projetos e relatórios de pesquisa em administração. 3.ed. Rio de Janeiro:Atlas, 2000.

VISSER, Jasper.Algumas Coisas Fáceis Para Fazer com as Novas Mídias. In: MENDES, L. (ed.) Reprograme Comunicação, Branding e Cultura Numa Nova Era de Museus. Rio de. Janeiro: Imã Editorial, 20 I2. Disponível em: http://reprograme.com. br/\#downloads .Acesso em: I4 fev. 2014.

VISSER, Jasper.The future of museums is about attitude, not technology. In: SANDERHOFF, Merete (ed.). Sharing is Caring: Openness and sharing in the cultural heritage sector. 20I4.Disponível em: https://www.smk.dk/en/article/the-sharing-is-caring-anthology/ .Acesso em: 9 jan. 2017.

VISSER, Jasper. The Museum of the future. Selected blogposts about museums in Times of social and technological change. 2017. Disponível em: http://themuseumofthefuture.com/tmotf_live_I2nu/wp-content/uploads/The-Museum-of-the-Future-Jasper-Visser.pdf. Acesso em: 30 mar 2020.

WEIL, S. Rethinking the Museum:And other meditations. Washington, DC: Smithsonian Institution Press, 1990.

WEIL, S. Beyond management: Making museums matter. Washington, DC: Smithsonian Institution Press, 2004. Disponível em: http://www.intercom.museum/ conferences/ 2000/weil.pdf. Acesso em: 29 jul. 2016. 